\title{
Mood Lability
}

National Cancer Institute

\section{Source}

National Cancer Institute. Mood Lability. NCI Thesaurus. Code C117252.

A condition of frequent mood changes associated with excessive emotional reactions. 